\title{
Silicosis prevalence and exposure-response relations in South African goldminers
}

\author{
G J Churchyard, R Ehrlich, J M teWaterNaude, L Pemba, K Dekker, M Vermeijs, N White, J Myers
}

Occup Environ Med 2004;61:81 1-816. doi: 10.1136/oem.2003.010967

See end of article for authors' affiliations

Correspondence to:

Prof. R Ehrlich, School of

Public Health and Family

Medicine, University of

Cape Town, Observatory

7925, South Africa;

ehrlich@cormack.uct.ac.za

Accepted 25 March 2004

\begin{abstract}
Aims: To measure the prevalence of silicosis among black migrant contract workers on a South African goldmine and to investigate exposure-response relations with silica dust.

Methods: In a cross sectional study, 520 black goldminers (aged >37 years) were interviewed and had chest radiographs taken. Silicosis was defined as International Labour Organisation Classification radiological profusion of $1 / 1$ or greater.

Results: Mean length of service was 21.8 years (range 6.3-34.5). The mean intensity of respirable dust exposure was $0.37 \mathrm{mg} / \mathrm{m}^{3}$ (range $0-0.70$ ) and of quartz $0.053 \mathrm{mg} / \mathrm{m}^{3}$ (range $0-0.095$ ). The prevalence of silicosis was $18.3-19.9 \%$ depending on reader. Significant trends were found between the prevalence of silicosis and length of service, mean intensity of exposure, and cumulative exposure.

Conclusion: Results confirm a large burden of silicosis among older black workers in the South African goldmining industry, which is likely to worsen as such miners spend longer periods in continuous employment in dusty jobs. An urgent need for improved dust control in the industry is indicated. If the assumption of stability of average dust concentrations on this mine over the working life of this group of workers is correct, these workers developed silicosis while exposed to a quartz concentration below the recommended occupational exposure limit (OEL) of $0.1 \mathrm{mg} / \mathrm{m}^{3}$. This accords with a mounting body of evidence that an OEL of $0.1 \mathrm{mg} / \mathrm{m}^{3}$ is not protective against silicosis.
\end{abstract}

$\Lambda$ Ithough South Africa has over a century of goldmining and silicosis experience, remarkably little is known about the prevalence of silicosis and specifically exposure-response relations for silicosis among black goldminers. ${ }^{12}$ Black goldminers are largely migrant contract workers originating from rural labour sending areas in Southern Africa, who have historically been employed in the dustier occupations and who have limited access to postemployment medical and compensation benefits. ${ }^{134}$

Lung diseases among black goldminers have also been less intensively studied than among white goldminers. ${ }^{1}$ A 1984 study of in-service black goldminers found a low prevalence of silicosis, $1.38 \%$, but did not stratify by length of service nor occupation. ${ }^{5}$ In contrast, two recent studies of ex-miners in labour sending areas of the Eastern Cape $^{4}$ and Botswana, ${ }^{6}$ found very high prevalences of radiological silicosis, of the order of $25 \%$. These findings raised controversy about the true extent and severity of silicosis among these migrant goldminers who make up $90 \%$ of the industry's workforce. ${ }^{78}$

Apart from studies of disease, there is also a paucity of published dust exposure data with which to judge the effectiveness of dust control strategies on the South African goldmines. The limited evidence that has been published suggests that there was little or no decline in mean underground dust levels on the goldmines between the 1940 s and 1990s. ${ }^{3}{ }^{10}$ This stasis, together with the progressive lengthening of the periods of continuous employment among returning contract workers since the 1970s, has led to the prediction of a high prevalence of silicosis in black goldminers in the latter part of the 20th century. ${ }^{2}$ In support of this contention, a recent autopsy study of in-service miners who died of trauma documented an increasing prevalence of histological silicosis between 1975 and 1991. ${ }^{11}$

The objectives of this study were to determine the prevalence of silicosis and to examine exposure-response relations between silica dust exposure and silicosis among inservice black goldminers over 40 years of age. This is the first
South African study to present dust exposure estimates for this population.

\section{METHODS}

\section{Subject selection}

A sequential sample of 520 black goldminers were recruited at a single goldmining company in the North West Province during their annual medical surveillance examinations between November 2000 and March 2001. Only miners over 40 years of age were invited to participate in order to target longer service workers and to make the study of exposureresponse associations more efficient. This procedure excluded employees on sick leave. A detailed labour history was taken from each employee and verified against records held by the company and the national mine labour recruiting organisation. Discrepancies were resolved by re-interviewing the employee. The miners were asked about smoking and any history of chest illness including tuberculosis. A full size posteroanterior chest radiograph was taken according to International Labour Organisation (ILO) specifications.

\section{Measurement of dust exposure}

In order to measure quartz (crystalline silica) exposures in current jobs under research conditions, a separate random sample of 100 employees were requested to participate in personal full shift gravimetric monitoring over a five day period ("research measurements"). Gilian air pumps were worn at waist height, after calibration on the surface to a flow rate of $1.9 \mathrm{l} / \mathrm{min}$, with samplers attached in the breathing zone. Miners who could not complete at least three full shift measurements were replaced by the next employee down the list in the same occupation. A total of 112 workers participated between July and December 2000, providing 506 dust measurements.

Gravimetric analysis of the dust samples was carried out by the company occupational hygiene department using a method set out in a procedure manual prepared for the study. 


\section{Main messages}

- The high prevalence (almost $20 \%$ ) of silicosis among older in-service black mineworkers confirms the existence of a significant epidemic of silicosis in the South African goldmining industry.

- Duration of exposure is an important determinant of the risk of silicosis within the narrow range of average dust concentrations measured. Consequently, as the average periods of service of black mineworkers continue to lengthen, the burden of silicosis will rise.

- If the assumption of historical stability of average silica concentrations is correct, these workers developed silicosis despite having been exposed to a mean quartz concentration below the South African mining occupational exposure limit of $0.1 \mathrm{mg} / \mathrm{m}^{3}$.

Determination of alpha quartz fraction was by $x$ ray diffraction, using a method approved by the Department of Minerals and Energy on the basis of comparisons carried out by the South African Bureau of Standards. This technique conforms in principle with the National Institute for Occupational Safety and Health (NIOSH) 7500 method, except that the dust is analysed directly on a $25 \mathrm{~mm}$ mixed cellulose acetate filter. Filters were pooled in batches of four or five by occupation prior to being sent for quartz analysis.

As the above dust survey covered only 26 of the 85 jobs represented in the sample of 520 miners chosen for medical examination, the data were supplemented by information from the company's mandatory dust surveillance programme ("routine measurements"). In this programme, employees are grouped into statistical populations according to assumed similarity of exposure. Five per cent of each such population is sampled every six months (with a minimum of five samples). Sampling is spread over all working shifts by random sampling. Employees wear Gilian air pumps fitted with $25 \mathrm{~mm}$ diameter Gilian cyclones. Gravimetric analysis is carried out on the mine by a trained occupational hygienist. For analysis of the alpha quartz fraction, at least five samples from each statistical population are randomly selected and pooled in each six month period. The method of quartz analysis is the same as described in the previous section. A total of 715 records were selected from this routine dataset of some 7700 records to represent the balance of the jobs not covered in the research dust study.

Respirable dust concentrations from both of the above data sources collected during varying shift periods were converted to eight hour time weighted average (TWA) concentrations. TWA quartz concentrations were calculated by applying the quartz fraction to the corresponding TWA respirable dust concentration. For some observations the quartz fraction in the dust was recorded as zero, so that the corresponding value for airborne quartz concentration was zero.

\section{Job exposure matrix and estimation of cumulative exposure}

The estimation of a job exposure matrix was required to attribute a dust concentration to each occupational exposure category. The matrix for dust and quartz was constructed by combining the data from the research and routine respirable dust and quartz tables. Where both tables had values for a particular occupation, a simple average of these values was calculated. Occupations not represented in the job exposure matrix were assigned a dust and quartz value by an occupational hygienist familiar with the mine, using already computed values from equivalent jobs.

\section{Policy implications}

- There is an urgent need for improved dust control strategies on the South African goldmines. This is made all the more pressing by the multiplicative interaction between silicosis and HIV infection in increasing the risk of pulmonary tuberculosis.

- The findings support the mounting evidence that a reduction of the occupational exposure limit for quartz to below $0.1 \mathrm{mg} / \mathrm{m}^{3}$ is indicated as part of a strategy to reduce substantially the risk of silicosis.

The 2733 cumulative jobs that the 520 miners had held were categorised into 22 occupational groupings for which gravimetric measurements were available, plus a large category of non-dusty jobs to which the value of zero dust was imputed. The following exposure variables were calculated. Length of service was the sum of all contract days worked in each occupation. Cumulative dust and cumulative quartz were the length of service in each job multiplied by the TWA concentration for dust or quartz respectively. Average intensity was the cumulative dust or cumulative quartz divided by the length of service.

\section{Reading of chest radiographs}

Chest radiographs were read according to the ILO Classification of Chest Radiographs of Pneumoconioses (ILO Classification) $)^{12}$ by two experienced readers, one currently and the other previously certified as NIOSH "B" readers. Inter-reader agreement was analysed by examining percentage agreement and the kappa statistic for chance corrected agreement.

\section{Analysis}

Histograms were constructed relating the prevalence of silicosis to length of service, and to cumulative exposure and average intensity for both respirable dust and quartz. For the dust variables, the association was examined across quintiles of the exposure metric. Logistic regression was used to examine exposure-response relations formally, using a single radiographic definition of silicosis based on the presence of parenchymal small opacities of rounded or mixed rounded/irregular shape at an ILO profusion level of $1 / 1$ and above. This cutpoint was used for comparability with a number of important studies ${ }^{16}$ and particularly with a prior South African study. ${ }^{13}$ For both respirable dust and quartz, length of service and average intensity were mutually adjusted. Age and a history of smoking were examined as potential confounders.

Ethics approval was obtained from the Research Ethics Committee of the Health Sciences Faculty of the University of Witwatersrand and from the Medical Research Ethics Committee of Anglogold Health Services. Written informed consent was obtained from each employee. Any employee found to have an abnormality was referred to the company clinical services for evaluation. Employees found to have a potentially compensable pneumoconiosis were referred for further assessment.

\section{RESULTS}

The research and routine quartz fractions and dust and quartz concentrations (table l) showed a high degree of concordance. For example, the research and routine mean TWA respirable dust concentrations were $0.35 \mathrm{mg} / \mathrm{m}^{3}$ (range $0.05-3.71$ ) and $0.36 \mathrm{mg} / \mathrm{m}^{3}$ (range $0.022-4.29$ ) respectively. 
Table 1 Dust and quartz concentrations and alpha quartz percentage

\begin{tabular}{lllll}
\hline & $\mathbf{n}$ & Mean & SD & Median \\
\hline Research dust measurements & & & 0.46 & 0.17 \\
TWA respirable dust concentration $\left(\mathrm{mg} / \mathrm{m}^{3}\right)$ & 506 & 0.35 & 0.46 & 13.2 \\
Alpha quartz fraction $(\%)$ & $497^{*}$ & 12.0 & 5.6 & $0.05-3.71$ \\
TWA respirable quartz concentration $\left(\mathrm{mg} / \mathrm{m}^{3}\right)$ & 497 & 0.048 & 0.072 & $0-21.3$ \\
Routine dust measurements & & & 0.71 \\
TWA respirable dust concentration $\left(\mathrm{mg} / \mathrm{m}^{3}\right)$ & 715 & 0.36 & 0.44 & 0.22 \\
Alpha quartz fraction $(\%)$ & $655^{*}$ & 16.0 & 5.8 & 16.1 \\
TWA respirable quartz concentration $\left(\mathrm{mg} / \mathrm{m}^{3}\right)$ & 715 & 0.051 & 0.072 & $0.022-4.29$ \\
\hline
\end{tabular}

TWA, 8 hour time weighted average; SD, standard deviation.

*Following pooling of batches of dust samples by occupation. Alpha quartz fraction for that batch attributed to each sample in the batch.

In keeping with the sampling strategy of including older, long service workers, the mean age was 46.7 years, the youngest being 37.1 years (table 2 ). Length of service ranged from 6.3 years to 34.5 years, with a mean of 21.8 years. The median number of jobs per subject was five. The average intensity of exposure per subject was low. For respirable dust, the highest average intensity was $0.7 \mathrm{mg} / \mathrm{m}^{3}$, with $90 \%$ of the workers having an average intensity of between 0.24 and $0.48 \mathrm{mg} / \mathrm{m}^{3}$ (not shown).

Of the group, 266 subjects ( $51 \%$ of the sample) had ever smoked, with $37 \%$ being current smokers. A total of 101 subjects (19.4\%) reported a history of tuberculosis, of whom nine workers were on antituberculous treatment at the time of the study.

Most of the films were of ILO quality 1 or 2. A total of 10 films were declared unreadable by one or both readers. The prevalence of any abnormality was high, with only $43.5 \%$ of the films read as completely normal by reader 1 and $38.8 \%$ by reader 2. Using an ILO cut point of profusion 1/1 or above, the prevalence of silicosis as assessed by reader 1 was $18.3 \%$ (95\% CI 15.0 to 21.9 ) and by reader 2 was $19.9 \%$ (95\% CI 16.5 to 23.6) (table 3). Of the 94 films read by reader 1 as $1 / 1$ or above, 49 were read in the more severe profusion categories 2 or 3-that is, 9.5\% overall. The equivalent for reader 2 was 53 of 102 films, $10.4 \%$ overall.

Agreement between readers was high. For a cut point of $1 / 1$ and above versus $1 / 0$ and below, concordance was $93.5 \%$ and kappa 0.79 (0.70-0.88), signifying excellent agreement. Only reader 1 's readings were therefore used for the exposure-response analysis, which is shown graphically for length of service and cumulative exposure to quartz in figs 1 and 2. Silicosis prevalence increased significantly with increasing length of service, from 1.6\% (1/59) among miners with less than 15 years of service to $47.6 \%$ (10/21) among workers with over 30 years of service $\left(p_{\text {trend }}<0.001\right)$. Similarly, a significant increase in silicosis prevalence was observed with increasing cumulative quartz exposure (fig 2) $\left(\mathrm{p}_{\text {trend }}<0.001\right)$.

The association between silicosis and each of the exposure variables was examined in logistic regression models

\begin{tabular}{|c|c|c|c|c|}
\hline \multirow[b]{2}{*}{ ILO category } & \multicolumn{2}{|c|}{ Reader 1} & \multicolumn{2}{|c|}{ Reader 2} \\
\hline & $\mathbf{n}$ & $\%$ & $\mathbf{n}$ & $\%$ \\
\hline $0,0 / 1$ & 392 & 76.1 & 394 & 76.8 \\
\hline $1 / 0$ & 29 & 5.6 & 17 & 3.3 \\
\hline $1 / 1,1 / 2$ & 45 & 8.7 & 49 & 9.5 \\
\hline 2 & 42 & 8.2 & 47 & 9.2 \\
\hline 3 & 7 & 1.3 & 6 & 1.2 \\
\hline Subtotal $\geqslant 1 / 1$ & 94 & 18.3 & 102 & 19.9 \\
\hline Total & 515 & 100.0 & 513 & 100.0 \\
\hline
\end{tabular}

ILO, International Labour Organisation.

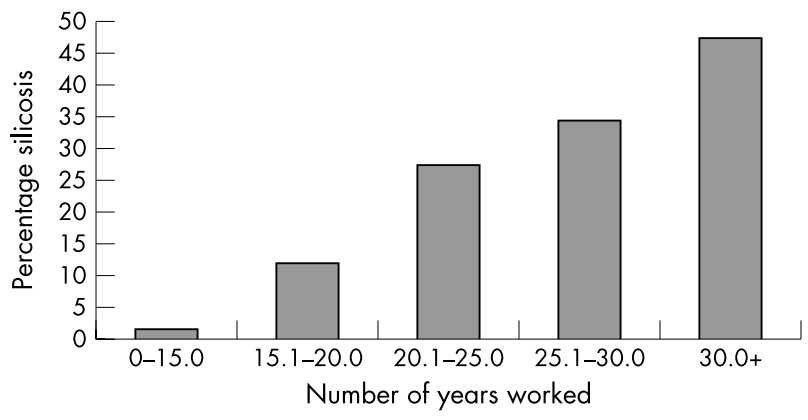

Figure 1 Prevalence of silicosis by length of service. Boundary values rounded off. Score test for trend of odds: $p=0.0000$.

(table 4). Because of the small numerical increment represented by a single year of service, the odds ratio for a five year increment in service is also presented. A statistically significant trend is observable for each exposure metric. For example, for each mg.year $/ \mathrm{m}^{3}$ of cumulative quartz exposure there is an increase in the odds of silicosis by 3.2 , compared to 1.2 for cumulative respirable dust. As neither age nor having ever smoked were independent predictors of silicosis in

Table 2 Age and exposure characteristics of study sample $(n=520)$

\begin{tabular}{|c|c|c|c|c|}
\hline & Mean & SD & Median & Range \\
\hline Age (years) & 46.7 & 4.4 & 46.1 & $37.1-59.9$ \\
\hline Duration of exposure (years) & 21.8 & 5.3 & 21.9 & $6.3-34.5$ \\
\hline Number of jobs & - & - & 5 & $1-16$ \\
\hline Cumulative exposure respirable dust (mg.years $/ \mathrm{m}^{3}$ ) & 8.2 & 2.88 & 7.95 & $0-22.68$ \\
\hline Average intensity respirable dust $\left(\mathrm{mg} / \mathrm{m}^{3}\right)$ & 0.37 & 0.096 & 0.36 & $0-0.70$ \\
\hline Cumulative exposure respirable quartz (mg.years $/ \mathrm{m}^{3}$ ) & 1.15 & 0.43 & 1.12 & $0-3.08$ \\
\hline Average intensity respirable quartz $\left(\mathrm{mg} / \mathrm{m}^{3}\right)$ & 0.053 & 0.015 & 0.051 & $0-0.095$ \\
\hline
\end{tabular}




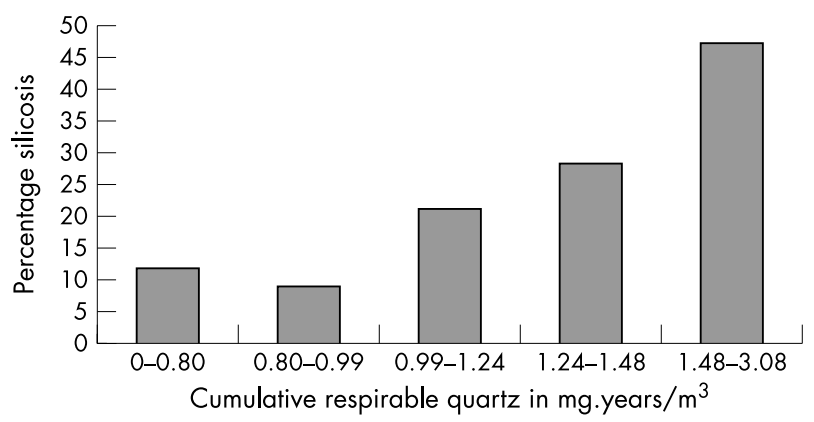

Figure 2 Prevalence of silicosis by cumulative quartz exposure, in quintiles. Boundary values rounded off. Score test for trend of odds: $\mathrm{p}=0.0000$.

exploratory analysis, no adjustment was carried out for these variables.

\section{DISCUSSION}

This study found a high prevalence of radiological silicosis among in-service black goldminers over 37 years of age (18.3-19.9\% depending on reader). Notably, approximately half of the silicosis films were classified at the ILO 2 or 3 level of profusion.

The only other published figures of silicosis prevalence among in-service black goldminers are $1.34 \%$ from a radiological survey in $1984^{5}$ and $9.3-12.8 \%$ histological silicosis in an autopsy series of trauma related deaths covering the period 1975-91. ${ }^{11}$ The earlier estimates included all miners irrespective of length of service, resulting in significantly lower prevalence estimates compared to that of the current study. However, another likely reason for an increase in silicosis prevalence between 1984 and the present is the continuing impact of stabilisation of the contract workforce. This process refers to an increase in the length of short term contracts, shorter periods of absence between contracts, and an increase in the overall length of service and age of the workforce. ${ }^{12}$ In the abovementioned autopsy study by Murray et al, the proportion of miners with 10 or more years of service increased from $10.8 \%$ in the $1975-79$ period to $29.5 \%$ in the $1990-91$ period. ${ }^{11}$

Since this was a cross sectional study, the prevalence of silicosis of $18.3-19.9 \%$ is likely to be an underestimate of the risk of silicosis in the underlying cohort of exposed miners. Under South African law, workers found to have silicosis plus tuberculosis are required to be excluded from further dusty work and are thus likely to be selected out of the workforce over time. In addition, quartz exposure carries a lifelong risk of incident silicosis even after exposure has ceased. ${ }^{13}{ }^{14}$

An illustration of the transfer of the silicosis burden to the ex-miner population of Southern Africa comes from comparing the prevalence in this study to that found in two survivor populations of ex-miners studied in their home districts. ${ }^{4} 6$ The prevalence in the Trapido et al $\operatorname{study}^{4}(\geqslant 1 / 1$, calculated from table II of that paper) was $26.3 \%$ (reader 1 ) and $20.6 \%$ (reader 2), a little higher than the figures in this study. In the Steen $e$ al study, ${ }^{6}$ only the prevalence $\geqslant 1 / 0$ was provided; this was $25.7 \%$ in the random sample component of that study, also a little higher than in this study: $23.9 \%$ (reader 1) and $23.3 \%$ (reader 2) (table 3 ).

Strengths of this study included detailed occupational histories validated against company records and a large gradient in duration of service. There was only one case of silicosis in the group with under 15 years of service. However, this cannot be interpreted as a threshold since there is no information on how many workers with fewer than 15 years of service had left mining work because of silicosis, nor the subsequent incidence of new silicosis appearing in this shorter service subcohort after they had left mining work. Interpretation of this finding with regard to a possible radiological threshold should also be tempered by the results of Murray and colleagues, ${ }^{11}$ who showed a prevalence of $9.7 \%$ histological silicosis in their autopsy series of in-service goldminers, most of whom had had fewer than 15 years of service.

The main limitation of the current study was that no historical dust data were available to construct a cumulative exposure index over the working lifetime of the group studied. Contemporary dust and quartz fraction measurements were used instead. To interpret these as a reflection of working lifetime exposure, the assumption has to be made that current and recent dust concentrations are a reasonable proxy for average dust concentrations experienced in those jobs over the previous two to three decades, and similarly for average quartz fractions. Although historical comparison is made difficult by differences in measurement technology, in the purpose of measurement and in methods of averaging data, there is some evidence for this "constancy" assumption. In a review of measurements taken for research and statutory purposes, Rendall (unpublished draft $\mathrm{PhD}$ dissertation, University of the Witwatersrand, 1999) cites mean respirable dust concentrations measured in 1977 and 1987-88 of the order of $0.4 \mathrm{mg} / \mathrm{m}^{3}$, only slightly higher than in this study $\left(0.35 \mathrm{mg} / \mathrm{m}^{3}\right.$, table 1$)$. Data derived from submissions to the Department of Minerals and Energy by goldmines for statutory compliance purposes for the period 1992-94 yielded a similar mean respirable dust concentration of $0.41 \mathrm{mg} / \mathrm{m}^{3}{ }^{10}$ Historical comparisons of airborne quartz concentrations are more problematic because of the additional variability of the quartz fraction of the dust. ${ }^{10}$ The mean quartz fractions measured in this study $(12-16 \%$, table 1) are in the same range as the fractions implied in the data cited by Rendall (unpublished draft $\mathrm{PhD}$ dissertation, University of the Witwatersrand, 1999) (10-20\%) and Kielblock and colleagues $^{10}(15 \%)$. The values of mean airborne quartz concentrations in this study $\left(0.05 \mathrm{mg} / \mathrm{m}^{3}\right)$ are a little lower than those cited in the above sources.

In examining exposure-response associations, a linear trend to increasing prevalence with increasing exposure was noted for all the exposure variables. This is illustrated

\begin{tabular}{|c|c|c|c|}
\hline & Odds ratio & $95 \% \mathrm{Cl}$ & p \\
\hline Length of service (per year)* & 1.11 & 1.06 to 1.17 & 0.00 \\
\hline Length of service (per 5 years)* & 1.69 & 1.34 to 2.15 & 0.00 \\
\hline Cumulative exposure respirable dust (per mg.year $/ \mathrm{m}^{3}$ ) & 1.2 & 1.1 to 1.3 & 0.00 \\
\hline Cumulative exposure quartz (per mg.year $/ \mathrm{m}^{3}$ ) & 3.2 & 1.9 to 5.4 & 0.00 \\
\hline Average intensity respirable dust $\left(\text { per } 0.01 \mathrm{mg} / \mathrm{m}^{3}\right)^{\star}$ & 1.03 & 1.005 to 1.05 & 0.02 \\
\hline Average intensity quartz (per $\left.0.01 \mathrm{mg} / \mathrm{m}^{3}\right)^{*}$ & 1.18 & 1.02 to 1.37 & 0.03 \\
\hline
\end{tabular}

*Length of service and average intensity mutually adjusted. Cumulative exposure examined in a model on its own. 
for length of service (fig 1) and cumulative quartz exposure (fig 2). The slopes of the exposure-response curves for average intensity (not shown) were rather flat compared to that for length of service. This suggests that within the narrow range of dust concentrations experienced by these goldminers, duration of exposure plays a major role in determining silicosis risk.

Despite the limitations of a prevalence survey, it is interesting to compare the prevalence figures obtained in this studies with earlier estimates of cumulative incidence of silicosis among white South African goldminers derived from two exposure-response studies, both predating the calendar period of exposure of the group studied in the current report. ${ }^{1315}$

Beadle et al studied a cohort of white miners exposed between the 1930s and 1960s. Using length of service as the predictor, after approximately 22.5 years of service the Beadle model predicts the cumulative incidence of silicosis as $10 \%$ or below on any of the dose-response curves he developed (each based on an average konimeter reading, ranging from 800 to 1800 ppcc)..$^{15}$ The current study found a prevalence of silicosis of $22 \%$ among workers in the stratum with a length of service of 20.1-25 years (fig 1). It would have taken closer to 30 years on Beadle's highest dust concentration curve to reach a cumulative incidence of silicosis of $22 \%$.

The cohort studied by Hnizdo and Sluis-Cremer ${ }^{13}$ were in employment between the early 1940s and early 1970s. These authors used cumulative respirable dust after treatment with heat and acid as their exposure variable, although it has recently been argued that they significantly underestimated dust exposure in their analysis. ${ }^{9}$ They reported a cumulative risk of silicosis (ILO $\geqslant 1 / 1$ ) of $25 \%$ at $9 \mathrm{mg}$.years $/ \mathrm{m}^{3}$, reached after an average of 28 years of exposure at an average respirable dust concentration of $0.33 \mathrm{mg} / \mathrm{m}^{3}$. The equivalent prevalence in the current study (stratum 8.6-10.4 mg.years/ $\mathrm{m}^{3}$, not shown) was $23 \%$, which is similar. However, the Sluis-Cremer and Hnizdo study entailed follow up of miners after they had left service. It is notable that the onset of $57 \%$ of the 313 cases of silicosis occurred after the miners had left the mines, detected when they returned at intervals for postemployment examinations to determine whether they had compensable disease. The prevalence figure in the current study is thus certainly an underestimate of lifetime cumulative incidence. If black miners selected out of the underlying cohort because of compensable disease were counted and those who left service for any reason were followed up for the same period and to the same degree as in the Hnizdo and Sluis-Cremer study, the incidence in this cohort would be higher than found in the earlier study. This would accord with the observation that black miners have historically held dustier jobs than white mineworkers, reflecting occupational stratification on the mines. In addition, at least until the early 1990s, the length of service of black applicants compensated for pneumoconiosis was on average 10 years shorter than that of white applicants. ${ }^{13}$

An important feature of the study was the very narrow range of average intensity of exposure for both respirable dust and quartz. For respirable dust exposure, $90 \%$ of the values for average intensity fell between 0.24 and $0.48 \mathrm{mg} / \mathrm{m}^{3}$. This range is entirely below the American Occupational Safety and Health Act and Mine Safety and Health Act exposure limit for quartz using the formula 10/(quartz fraction plus $2),{ }^{16}$ assuming a quartz fraction of $13.2 \%$ (derived from table 1).

Similarly, for the average intensity of quartz exposure, the median value in this study was approximately $0.05 \mathrm{mg} / \mathrm{m}^{3}$, the occupational exposure limit recommended by NIOSH and the American Conference of Governmental Industrial Hygienists (itself reflecting a technical measurement limit). ${ }^{16}$
A total of $90 \%$ of the subjects had an average intensity of quartz exposure which fell between 0.029 and $0.075 \mathrm{mg} / \mathrm{m}^{3}$, well below the South African mining occupational exposure limit (OEL) of $0.1 \mathrm{mg} / \mathrm{m}^{3}$. As suggested from the comparison with industry-wide data earlier, it is possible that the quartz exposures measured in this study underestimated the historical quartz exposures of this workforce, whether due to measurement variability or recent improvement in dust control. However, the distributions of quartz concentrations in the goldmines, available from industry data only for the 1990s, indicate that of the order of $87 \%{ }^{17}$ to $93 \%{ }^{10}$ were below $0.1 \mathrm{mg} / \mathrm{m}^{3}$. It is therefore a reasonable to conclude that despite working in the "protective" range of exposure, $18.3-19.9 \%$ of these older mineworkers had developed silicosis. Further, half of these cases had reached ILO profusion levels of 2 and 3, signifying more advanced radiological disease.

In conclusion, this is the first study of exposure-response relations for silicosis in black South African goldminers using dust exposure data. Almost one in five of these older, longer service black mineworkers had developed silicosis. Allowing for the fact that the sample in this study was chosen to represent older mineworkers, if one extrapolates these results to the goldmining industry in general, they confirm the existence of a significant epidemic of silicosis in the industry and a compelling need for improved dust reduction strategies. A further conclusion of the study is that within the narrow range of average dust concentrations, duration of exposure is an important determinant of the risk of silicosis in this population. This implies that with the lengthening of the average length of service of black mineworkers, the burden of silicosis will continue to rise.

This need to control silica exposure is all the more urgent in the current era of an increasing prevalence of HIV infection among mineworkers. HIV infection greatly increases susceptibility to tuberculosis. A recent study ${ }^{18}$ of the effect of HIV infection and silicosis on tuberculosis incidence in South African goldminers found that HIV infection increased the incidence of tuberculosis by fivefold and silicosis increased the incidence of tuberculosis threefold. The combined effect of HIV and silicosis showed multiplicative interaction by increasing the incidence of tuberculosis by 15 times.

Finally, if the assumption of unchanged dust concentrations on this mine over the past 30 years is correct, these workers developed silicosis despite having been exposed to quartz concentrations below the recommended OEL of $0.1 \mathrm{mg} / \mathrm{m}^{3}$. This is in accord with a mounting body of evidence that an OEL of $0.1 \mathrm{mg} / \mathrm{m}^{3}$ is not protective against silicosis and that an OEL of $0.05 \mathrm{mg} / \mathrm{m}^{3}$ may not be protective against silicosis either. No exposure threshold could be determined as the many sources of measurement variability and assumptions in grouping the dust data make distinctions between relatively small increments in average quartz intensity subject to error. The findings nevertheless support the conclusion of Hnizdo and Sluis-Cremer 10 years ago, ${ }^{13}$ as well as that of NIOSH and a number of recent commentators, ${ }^{16} 1920$ that a reduction of the quartz OEL below $0.1 \mathrm{mg} / \mathrm{m}^{3}$ is indicated as part of a strategy to reduce substantially the risk of silicosis and its complications.

\section{ACKNOWLEDGEMENTS}

We would like to thank the staff of Aurum Health Research, West Vaal Hospital Occupational Health Centre, and West Vaal Region Occupational Hygiene Department for their assistance in conducting this study. We acknowledge Prof. Mary Ross for her support during the conduct of this study, Anna Trapido for doing the original literature review, Marco Biffy for providing the method for and carrying out the quartz fraction analysis, and Anglogold and Anglogold Health Service for their permission to publish the data. This study was commissioned and funded by the Mine Health and 
Safety Council as HEALTH 606 within the research programme of the Safety in Mines Research Advisory Committee (SIMRAC).

\section{Authors' affiliations}

G J Churchyard, L Pemba, Aurum Health Research, Orkney, South Africa

K Dekker, M Vermeijs, Occupational Hygiene, Anglogold, South Africa R Ehrlich, J M teWaterNaude, J Myers, School of Public Health and Family Medicine, University of Cape Town, Cape Town, South Africa N White, Lung Institute, University of Cape Town, Cape Town, South Africa

\section{REFERENCES}

1 White N. Health hazards in the mining industry: an overview. A submission to the Commission of Inquiry into Health and Safety in the Mining Industry. Leon RN, chairperson. Pretoria: Department of Mineral and Energy, 1995.

2 Leger J-P. Occupational diseases in South African mines-a neglected epidemic. S Afr Med J 1992;81:197-201.

3 Republic of South Africa. The Commission of Inquiry into Health and Safety in the Mining Industry, Leon RN, chairperson. Pretoria: Department of Minerals and Energy, 1995.

4 Trapido A, Mqogi NP, Williams G, et al. Prevalence of occupational lung disease in a random sample of former mineworkers, Libode District, Eastern Cape Province, South Africa. Am J Ind Med 1998;34:305-13.

5 Cowie RL, Van Schalkwyk MG. The prevalence of silicosis in Orange Free State gold miners. J Occup Med 1987;29:44-6.

6 Steen TW, Gyi KM, White NW, et al. Prevalence of occupational lung disease among Botswana men formerly employed in the South African mining industry. Occup Environ Med 1997;54:19-26.

7 Le Grange MAC. Occupational lung disease among ex-mineworkers [letter]. $S$ Afr Med J 1996;86:841

8 White N. Occupational lung disease in ex-mineworkers-who answers the alarm? [letter]. S Afr Med J 1996;86:1127.
9 Gibbs GW, Du Toit RSJ. Estimating the quartz exposure of South African gold miners. Ann Occup Hyg 2002;46:597-607.

10 Kielblock AJ, Franz RM, Unsted AD, et al. Quantitation of occupational health risks in the South African mining industry and assessment of sources of uncertainty in the estimates. Johannesburg: Council for Scientific and Industrial Research Division of Mining Technology, 1997.

11 Murray J, Kielkowski D, Reid P. Occupational disease trends in black South African gold miners. An autopsy based study. Am J Respir Crit Care Med 1996;153:706-10.

12 International Labour Office. Guidelines for the use of ILO international classification of radiographs of pneumoconioses. Occupational Safety and Health Series No. 22. Geneva: ILO, 1980.

13 Hnizdo E, Sluis-Cremer G. Risk of silicosis in a cohort of white South African gold miners. Am J Ind Med 1993;24:447-57.

14 Chen W, Zhuang Z, Atffield MD, et al. Exposure to silica and silicosis among tin miners in China: exposure-response analyses and risk assessment. Occup Environ Med 2001;58:31-7

15 Beadle DG, Harris E, Sluis-Cremer GK. The relationship between the amount of dust breathed and the incidence of silicosis: an epidemiological study of South African European gold miners. In: Shapiro HA, ed. Pneumoconiosis: Proceedings of the International Conference, Johannesburg, 1969. Oxford: Oxford University Press, 1971:473-7.

16 National Institute for Occupational Safety and Health (NIOSH). Health effects of occupational exposure to respirable crystalline silica. Publication No. 2002-129. Cincinnati, OH: Department of Health and Human Services (NIOSH), 2002:1-127.

17 Rees D, Kielkowski D, Lowe R, et al. A report on occupational health indicators for South Africa, Part II. NCOH Report 1/99. Johannesburg: National Centre for Occupational Health, 1999.

18 Corbett EL, Churchyard GJ, Clayton TC, et al. HIV infection and silicosis: the impact of two potent risk factors on incidence of mycobacterial disease in South African miners. AIDS 2000;14:2759-68.

19 Sherson D. Silicosis in the twenty first century. Occup Environ Med 2002;59:721-2.

20 Greaves IA. Not-so-simple silicosis: a case for public health action. Am J Ind Med 2000;37:245-51. 


\section{Correction}

GJ Churchyard, R Ehrlich, J M teWaterNaude, et al. Silicosis prevalence and exposure-response relations in South African goldminers. Occup Environ Med 2004;61:811-6.

Figure 1 in this paper overstated the silicosis prevalence in the last three strata of the bar graph owing to errors in the denominators used. Table 1 below contains the correct prevalences which replace those derivable from the published Figure 1 . The interpretation of study findings remains unchanged.

Table 1 Prevalence of silicosis by length of service

\begin{tabular}{lrccc}
\hline $\begin{array}{l}\text { Number of } \\
\text { years worked }\end{array}$ & $\mathbf{n}$ & Silicosis & Corrected prevalence (\%) & $\begin{array}{l}\text { Published prevalence derivable } \\
\text { from Figure 1 (\%) [1] }\end{array}$ \\
\hline $0-15.0$ & 59 & 1 & 1.69 & 1.69 \\
$15.1-20.0$ & 120 & 13 & 10.83 & 10.83 \\
$20.1-25.0$ & 195 & 42 & 21.53 & 27.45 \\
$25.1-30.0$ & 105 & 27 & 25.71 & 34.61 \\
$30.0+$ & 31 & 10 & 32.25 & 47.61 \\
\hline
\end{tabular}

Boundary values rounded off. Score test for trend of odds: $p=0.0000$.

Correspondingly, the text on page 3 of the original publication needs to be amended as follows: "Silicosis prevalence increased significantly with increasing length of service, from $1.69 \%(1 / 59)$ among miners with 15 years of service or less to $32.2 \%(10 / 31)$ among workers with over 30 years of service $(\mathrm{p}<0.001)$."

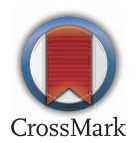

Occup Environ Med 2015;72:78. doi:10.1136/oem.2003.010967corr1 